\title{
Energy Saving from Cloud Resources for a Sustainable Green Cloud Computing Environment
}

\begin{abstract}
Karuppasamy M. and Balakannan S. P.
Kalasalingam University, Tamil Nadu, India

E-mail: karuppasamy.m1987@gmail.com; balakannansp@gmail.com

Received 05 January 2018; Accepted 22 March 2018;

Publication 20 April 2018

Abstract

Cloud computing services are proliferation. The Cloud computing resources face major pitfall in energy consumes. The prime of energy consumption in cloud computing is by means of client computational devices, server computational devices, network computational devices and power required to cool the IT load. The cloud resources contribute high operational energy cost and emit more carbon emission to the environment. Therefore the cloud services providers need green cloud environment resolution to decrease the operational energy cost along with environmental impact. The most important objective of this effort is to trim down the energy from utilized and unutilized (idle) cloud resources and save the energy in cloud resources efficiently. To achieve the sustainable green cloud environment from an Energy Saving Algorithm used to choose the appropriate virtual services so that the power at the client, server, and network recourses can be reduced.
\end{abstract}

Keywords: Cloud Computing, Green, Environment, Virtualization, Energy.

\section{Introduction}

Cloud computing is a shared computing environment, that gives a variety of technology and service through on-demand basics. Cloud computing

Journal of Cyber Security and Mobility, Vol. 7_1, 95-108. River Publishers doi: $10.13052 /$ jcsm2245-1439.718

This is an Open Access publication. (c) 2018 the Author(s). All rights reserved. 
provides infrastructure, platform, and software (application) as offerings to the cloud customers. Cloud computing utilizes of computing resources just like hardware, software, networking which can be shared as a service over the internet [1]. Cloud deployment models such as Public model deploy large cloud infrastructure resources and services to the users. Private model is used to create a private network. It is just within an organization's framework. Community model is used to share infrastructure resources to cloud users. Hybrid model is a mixture of two or more cloud operation and resource management may be internal or external [2].

The highest increase in internet utilization is growing every year at the same time the on-demand for cloud computing provider company is also multiplied thereby growing the on-demand cloud computing services. The cloud service provider builds large cloud data center and provides high resources provisioning which requires a major amount of power to be operated for the cloud computing resources and consequently lot of energy is consumed [3]. The energy can be saved via using a shrinking quantity of resources that satisfy the workload requirement; for that reason, needless resources are switched off or placed into the low power mode whilst the workload requires lower. And similarly when the workload increases the extra resources are switched on or placed into high electricity mode [4].

While the usage of cloud computing resources we might be conscious that, there are numerous troubles and amazing energy intake, carbon dioxide emission and allied prices issues. Therefore for the operation and maintenance of cloud resources, cloud service companies are getting extremely stricken [5]. The cloud customers utilize the entire sources provided by the cloud carriers. Nevertheless, electrical power obsessive with the aid of cloud information facilities continues to be inside the categorize of lots of megawatts [6].

The Recent advances in computing useful resource technology have enhanced the energy intake hassle to an actual level. On the other hand, it still stays a vital difficulty for resources computing as a result of the quantity of electricity obsessive with the aid of computing sources is affected first and essential by means of their usage styles. In numerous phrases, useful resource beneath-usage or over-loading suffers a higher volume of electricity use evaluate with efficaciously utilize resources. This involves the occasion of assorted power-saving techniques besides programming, virtualization, and consolidation [7].

The computing Resources are the coronary heart of cloud computing. The resource usage not at all steps so long as sources are confined compared to the boom in demand for computers and computing. Resources are shared to 
supply multiple clients the use of a multi-tenant model, with distinct bodily and virtual resources with dynamism assigned and reassigned in step with client call for [8].

Cloud uses thousands of resources to provide the services to the user and to run different categories, that resources consume bulkiness quantity of power is used for cooling and another process in recent years. There are different hardware technology like virtualization, containers and software technology like software efficient algorithm used to decrease the consumption of energy [9]. The strength green cloud may be achieved by optimizing the energy intake shrinking and enhancing the effectiveness of cooling and electricity offering facility in the cloud data center resource. In latest year, the cloud sources fed on around 1.1\%-1.5 percent of worldwide energy. The pike research forecast the cloud assets eat of almost 140Twh in 2020 [10].

The green cloud computing is visualized in the direction of realizing not solely the economical process and consumption of computing resources however conjointly to reduce energy consumption. The most objective of inexperienced cloud computing is energy aware resources management, economic policies and algorithmic rule for virtualization, resources provisioning, resources allocation, employment and task consolidation in cloud atmosphere which will be and a lot of property and eco-friendly mainstream technology for a future generation [11].

The resource allocation is a valuable way to handle resources particularly for the cloud, both in the tiny period and long period usage of cloud resources. The power green utilization of cloud assets to cope with reducing the number of energetic cloud resources and placing surplus resources right into a power saving mode or maybe turning off some idle resources [12]. Analytically the cloud services provided to the resources in both short period and long period usages of cloud resources face the problem like the excessive of operation cost due to the over resources provisioning [13].

\section{Related Work}

Resource allocation is one of the challenges of cloud surroundings as a result of the client can get access to resources from anywhere and at any time. In a cloud, the key challenge is that the allocation of resources among the user having dynamic requests of resources supported their application usage patterns. The unreliable and dynamic requests got to be compelled to run on cloud resources across the net. The resource is unbelievably necessary as one thing like central processing unit, memory, storage, and information measure 
associated application is usually termed an information and communication technology resource at intervals the cloud surroundings [14]. The matter of resource allocation is quite expensive and desires some assumptions along with a set of workflow tasks for resource requirements, set of working servers, task consolidation meeting service level agreement, and reduction in power wastage and resource usage costs. The resource allocation inconvenience involves the acceptable provisioning and economical use available resources for applications the resource allocation drawback square measure to boot strictly due to the workloads that cause utterly totally unusual resource demands from service suppliers for the cloud [15].

The resource allocation has a partial range of servers or physical machines that square measure switched to the sleep mode to avoid wasting energy till a virtual machine is allotted to them. To use the smallest amount range of PMs that square measure enough to run a range of VMs in a very dynamic system, whereas no previous data of VMs usage throughout the system run, considering SLA violation and performance degradation. It's supposed once running the two algorithms that every VM is combined with just one request, that victimization area shared requests allocation [16]. The resource allocation algorithmic program is dead for mapping all requests sent to the information center over the smallest amount range of PMs. Then the server consolidation algorithmic program is dead in the case of any VM unleash, to ensure continuous energy economical use of the system resources. Conjointly, minimizing the number of migrations is another important goal taken into the system's thought, whereas migration method takes time and has the value that affects system performance, diagrammatic in task completion times [17].

Power consumption in cloud information center, large-scale, enterprise, disk-based backup storage devices. The storage devices power management has mostly centered on managing disk power consumption. Those as storage devices scale their capability chiefly backup and deposit systems. The quantity of disks can increase the purpose wherever disks area unit the dominant power shoppers. The various drives to stay as power-on once not utilized. The deposit systems use information placement, scrubbing, and recovery techniques that alter several of the drives within the system [18].

The cloud network infrastructure faces the network connections, issues attributable to the increasing quality and information measure demands of package applications can become additional and additional jammed with dynamic applications within the network. The trend currently towards cloud computing is resulting in additional traffic and additional congestion incidence within the network. In a very cloud infrastructure, in several cases, congestion 
might not be simply foreseen [19]. Cloud computing could simply increase the value of communication if network improvement isn't properly enforced. Once the cloud applications area unit response-dependent, network connections from end-to-end area unit crucial to stop applications from temporal order out, corrupting information, or forestall employees at remote sites. Applications area unit like virtualized server applications and software-asa-service running within the cloud network needs additional information measure [20].

In cloud atmosphere middle layer between the cloud servers and therefore the client's requests which will perform the allocation of the processes to multiple clouds in overload and under load conditions. Because the request is performed by the user, sure parameters area unit outlined with every user request just like the information point in time, information method time, deadline, input-output specifications [21]. Resource allocation is performed consecutive, and every method should be dead at intervals the point. If over one method should be dead at a similar time, therefore method migration from a cloud to a different takes place [21].

\section{Green Cloud Environment}

Energy consumption of the computing devices and the resource utilization has a strong relationship with the power wattage formula as shown below.

$$
\begin{aligned}
& P=E / T \\
& E=P * T
\end{aligned}
$$

Where the Power measured by P, amount of time measured by T, and energy measured by $\mathrm{E}$. The distinction between power and energy is incredibly vital since reduce of the power utilization does not until the end of time to cut the consumed energy [22].

To save the amount of energy consumed by the cloud resources were too established by the green cloud environments. The cloud resources contain the various categories of nodes, servers, process units, network topology, and power contribution unit and storage facility the taken as a whole power consumption at the cloud infrastructure can be given by the formula

$$
E C R=E N+E N E T+E S+E S D+E O E
$$

$\mathrm{E}_{\mathrm{CR}}$-Cloud Resources energy, EN-Energy Consume form node, EN-Energy Consume form network, ES-Energy consumes from the server, ES-Energy 
consumes from storage devices, EO-Energy consumes from other electrical equipment. The total energy exploitation of physical resources consists of two elements as Estatic and $\mathrm{E}_{\mathrm{VM}}$. The Estatic is that the fastened power of a server in spite of running $\mathrm{VMs}$ or not and $\mathrm{E}_{\mathrm{VM}}$ is that the dynamic power that is compulsive by VMs running thereon. Suppose there are $\mathrm{nVM}$

$$
\text { Etotphy }=\text { Estatic }+\sum E v m=\text { Estatic }+\sum_{i}^{n} E v m i
$$

$\mathrm{E}_{\mathrm{VMi}}$ can be additional rotten keen on the energy consumption of device such as IO, CPU, and memory denoted by the Ecpu, VMI, Emem VMI, EIO VMI. The EIO VMI includes the common energy cost of all devices that involve IO Operation such as disk and network data transfers. The energy consumption of VMI is

$$
E v m i=E_{v m i}^{c p u}+E_{v m i}^{m e m}+E_{v m i}^{I O}
$$

The workload of cloud resources like CPU, disk storage, and Network interfaces and build description on shift nodes on/ off to attenuate the general energy consumption. The cloud network switches unit of measurement with dynamism reconfigured to change the activity of the server once necessary. The energy consumption is reduced by shift inactive to power saving mode (sleep, hibernation) [23].

\section{Energy Saving Algorithm}

In cloud computing environment face one of the major troubles is the energy consumption. The energy saving algorithm used to save the energy from idle cloud resources. To saving the energy means decreasing the amount of energy used while achieving a similar outcome.

Step-1 To identify the resources and available resources.

Step-2 To calculate every resources processing time.

Step-3 To calculate arrival task size processing time.

Step-4 Total no. of the task with size processing time

$$
\sum \text { Total no. of resources with processing time. }
$$

Step-5 To allocate the entire task with resources processing time.

Step-6 To unallocated resources moves to the idle stage and save the energy. Step-7 To repeat the step-1 to step- 6 for further allocation. 
This energy saving algorithm starts by finding the arrival job and size of the job, how long to utilize the particular resources in the cloud infrastructure resources. Each resource contains separate workspace. The energy saving algorithm can solve very complex issues such as finding the resource allocation in the cloud computing system. The unallocated resource is identified and the route is powered off. But if the input package size exceeds the current utilized resource, the unutilized resource will be switched on in the next generation.

\section{Figures and Tables}

Table 1 Cloud Resources Energy Utilization

\begin{tabular}{|c|c|c|}
\hline Resource & Nos & $=$ Energy (in Terms of Power Consumption Approximately) \\
\hline Router/Switch & 25 & $\begin{array}{l}20 * 25=500 \text { watts }(\mathrm{in} \mathrm{hr}) * 24(\mathrm{hr})=12000 \text { watts } * 365 \text { (days) } \\
=4380000 \text { watts (year) }\end{array}$ \\
\hline Node & 10 & $\begin{array}{l}100 * 10=1000 \text { watts }(\mathrm{in} \mathrm{hr}) * 24(\mathrm{hr})=24000 \text { watts } * 365(\text { days }) \\
=8760000 \text { watts (year) }\end{array}$ \\
\hline Server & 2 & $\begin{array}{l}850 * 2=1700 \text { watts }(\mathrm{in} \mathrm{hr}) * 24(\mathrm{hr})=40800 \text { watts } * 365(\text { days }) \\
=14892000 \text { watts (year) }\end{array}$ \\
\hline $\begin{array}{l}\text { Storage Devices } \\
\text { (Rack) }\end{array}$ & 2 & $\begin{array}{l}2 * 1200=2400 \text { watts }(\mathrm{in} \mathrm{hr}) * 24(\mathrm{hr})=57600 \text { watts } * 365(\text { days }) \\
=21024000 \text { watts }(\text { year })\end{array}$ \\
\hline
\end{tabular}

From Table 1, it can be observed that the some cloud resources power (energy) utilization performance measured by watts in hour. The resources are consuming more energy when the resources not utilized.

Table 2 Green Cloud Resources Energy Utilization

\begin{tabular}{llcll}
\hline & & \multirow{2}{*}{$\begin{array}{c}\text { No. of } \\
\text { Resources Kept }\end{array}$} & \multicolumn{2}{c}{ Energy (Power Consumption Apex) } \\
\cline { 4 - 5 } Resource & Nos & Switched Off & On Stage (per Hour) & $\begin{array}{l}\text { Off Stage (Saving) } \\
\text { (per Hour) }\end{array}$ \\
\hline Router/Switch & 25 & 15 & $15^{*} 20=300$ watts & $10 * 20=200$ watts \\
Node & 10 & 5 & $5^{*} 100=500$ watts & $5 * 100=500$ watts \\
Server & 2 & 1 & $1 * 850=850$ watts & $1 * 850=850$ watts \\
Storage Devices & 2 & 1 & $1 * 1200=1200$ watts & $1 * 1200=1200$ watts \\
\hline
\end{tabular}

From Table 2, it can be observed that the some green cloud resources power (energy) utilization performance measured by watts in hour. An energy efficient control in a green cloud resource with three operating modes as high utilization, idle, sleep. Where a sleep mode would be responsible for 
saving power consumption. A resource is allowed to stay in an idle mode for short time when there was no job in the resource rather than switch suddenly into a sleep mode right away when the resource becomes empty. The main technique applied to minimize power consumption is concentrating the workload to the minimum of physical resources and switching idle nodes off. The cloud resources are dynamically reconfigured to change the active set of the server when necessary. Energy consumption is reduced by switching the idle resources to power saving mode high utilization, idle, sleep.

Figures 1 and 2 show the cumulative distribution of the utilization of power (energy) consumption of cloud resources, green cloud resources respectively.

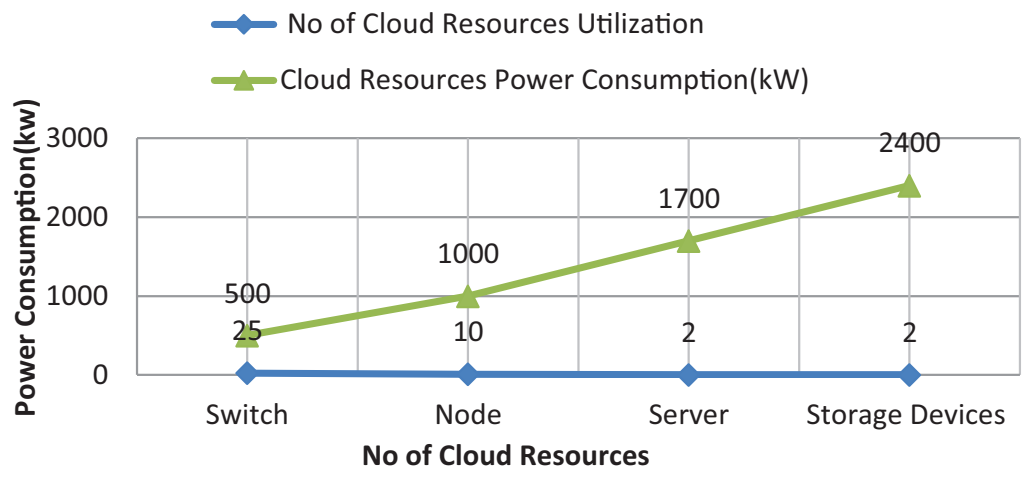

Figure 1 Cloud Power Utilization.

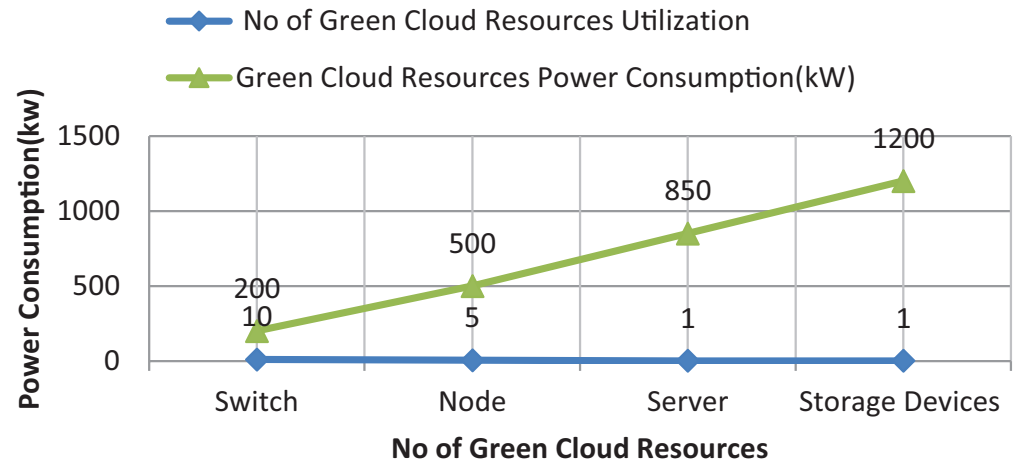

Figure 2 Green Cloud Power Utilization. 
It demonstrates that the cloud resources with high utilization and low utilization in both green cloud and cloud environment. The metric of effective resources utilization, which indicates the average utilization ratio of all the active resources. As aforementioned, a higher effective resources utilization ratio of resources indicates more efficient energy usage of cloud resources.

\section{Conclusion}

The most important confront at the present in Green Cloud Environment is changing from energy efficiency to energy sustainability. The simulation work confirms that the numbers of cloud resources utilization that can be used are minimized to a considerable amount thereby reducing the energy utilized for the resources. The proposed system helps cloud turn to green by applying an energy saving algorithm. Energy saving algorithm aims to allocate the minimum number of resources to utilize entire cloud infrastructure environments. This work can be extended to the real cloud environment for reducing the resources utilization thereby saving energy and earth.

\section{References}

[1] Buyya, R. (2013). Introduction to the IEEE Transactions on Cloud Computing. IEEE Transactions on Cloud Computing, 1(1), 3-21.

[2] Lee, Y. C., and Zomaya, A. Y. (2012). Energy Efficient Utilization of Resources in Cloud Computing Systems. The Journal of Supercomputing, 60(2), 268-280. doi: 10.1007/s11227-010-0421-3

[3] Buyya, R., Yeo, C. S., Venugopal, S., Broberg, J., and Brandic, I. (2009). Cloud Computing and Emerging IT Platforms: Vision, Hype, and Reality for Delivering Computing as the 5th Utility. Future Generation computer systems, 25(6), 599-616.

[4] Farahnakian, F., Ashraf, A., Pahikkala, T., Liljeberg, P., Plosila, J., Porres, I., and Tenhunen, H. (2015). Using Ant Colony System to Consolidate VMs for Green Cloud Computing. IEEE Transactions on Services Computing, 8(2), 187-198.

[5] Buyya, R., Beloglazov, A., and Abawajy, J. (2010). Energy-Efficient Management of Data Center Resources for Cloud Computing: a Vision, Architectural Elements, and Open Challenges. arXiv preprint arXiv:1006.0308. Las vegas. 
104 Karuppasamy M. and Balakannan S. P.

[6] Boru, D., Kliazovich, D., Granelli, F., Bouvry, P., and Zomaya, A. Y. (2015). Energy-efficient Data Replication in Cloud Computing Datacenters. Cluster computing, 18(1), 385-402.

[7] Lee, Y. C., and Zomaya, A. Y. (2012). Energy Efficient Utilization of Resources in Cloud Computing Systems. The Journal of Supercomputing, 60(2), 268-280.

[8] Ala'a Al-Shaikh, H. K., Sharieh, A., and Sleit, A. (2016). Resource Utilization in Cloud Computing as an Optimization Problem. Resource, 7(6).

[9] Shaikh, F. K., Zeadally, S., and Exposito, E. (2017). Enabling Technologies for Green Internet of Things. IEEE Systems Journal, 11(2), 983-994.

[10] The Environmental Protection Agency (EPA) estimated one kilowatthour produces 1.52 pounds of carbon dioxide (excluding line-losses)

[11] Beloglazov, A., Abawajy, J., and Buyya, R. (2012). Energy-Aware Resource Allocation Heuristics for Efficient Management of Data Centers for Cloud Computing. Future generation computer systems, 28(5), $755-768$.

[12] Lee, Y. C., and Zomaya, A. Y. (2012). Energy Efficient Utilization of Resources in Cloud Computing Systems. The Journal of Supercomputing, 60(2), 268-280.

[13] Boru, D., Kliazovich, D., Granelli, F., Bouvry, P., and Zomaya, A. Y. (2015). Energy-Efficient Data Replication in Cloud Computing Datacenters. Cluster computing, 18(1), 385-402. doi:10.1007/s10586-0140404-X

[14] Hsu, C. H., Slagter, K. D., Chen, S. C., and Chung, Y. C. (2014). Optimizing Energy Consumption with Task Consolidation in Clouds. Information Sciences, 258, 452-462.

[15] Cao, Z., Lin, J., Wan, C., Song, Y., Zhang, Y., and Wang, X. (2017). Optimal Cloud Computing Resource Allocation for Demand Side Management in Smart Grid. IEEE Transactions on Smart Grid, 8(4), 1943-1955.

[16] Mastroianni, C., Meo, M., and Papuzzo, G. (2013). Probabilistic Consolidation of Virtual Machines in Self-Organizing Cloud Data Centers. IEEE Transactions on Cloud Computing, 1(2), 215-228.

[17] Kaur, T., and Chana, I. (2016). Energy Aware Scheduling of DeadlineConstrained Tasks in Cloud Computing. Cluster Computing, 19(2), 679-698. doi: 10.1007/s10586-016-0566-9 
[18] Hameed, A., Khoshkbarforoushha, A., Ranjan, R., Jayaraman, P. P., Kolodziej, J., Balaji, P., and Khan, S. U. (2016). A Survey and Taxonomy On Energy Efficient Resource Allocation Techniques for Cloud Computing Systems. Computing, 98(7), 751-774. doi: 10.1007/s00607014-0407-8

[19] Josphin, J., Suprakash, S., and Balakannan, S. P. (2015). An Optimal Virtual Machine Assignment Using Firefly Algorithm For Achieving Energy Efficiency In Data Center. International Journal of Applied Engineering Research, 10(5) 0973-4562.

[20] Bianzino, A. P., Chaudet, C., Rossi, D., and Rougier, J. L. (2012). A Survey of Green Networking Research. IEEE Communications Surveys and Tutorials, 14(1), 3-20.

[21] Fiandrino, C., Kliazovich, D., Bouvry, P., and Zomaya, A. (2015). Performance and Energy Efficiency Metrics for Communication Systems of Cloud Computing Data Centers. IEEE Transactions on Cloud Computing.

[22] Sofia, A. S., and Kumar, P. G. (2015). Implementation of Energy Efficient Green Computing in Cloud Computing. International Journal of Enterprise Network Management, 6(3), 222-237.

[23] Gu, C., Huang, H., and Jia, X. (2014). Power Metering for Virtual Machine in Cloud Computing-Challenges and Opportunities. IEEE Access, 2, 1106-1116.

[24] Liu, X. F., Zhan, Z. H., Deng, J. D., Li, Y., Gu, T., and Zhang, J. (2018). An Energy Efficient Ant Colony System for Virtual Machine Placement in Cloud Computing. IEEE Transactions on Evolutionary Computation. 22(1).

[25] Karuppasamy, M., Suprakash, S., Balakannan, S. P., and Krishnankoil, S. (2013). Energy Efficient Cloud Networks Towards A Sustainable Green Environment. environment, 7, 8. 2320-8791

[26] Wang, W., Liang, B., and Li, B. (2015). Multi-Resource Fair Allocation in Heterogeneous Cloud Computing Systems. IEEE Transactions on Parallel and Distributed Systems, 26(10), 2822-2835.

[27] Shameer, A. P., Haseeb, V. V., and Mini Mol, V. K. (2015). Green Approach for Reducing Energy Consumption-A Case Study Report. International Journal, 5(1).

[28] Quang-Hung, N., Thoai, N., and Son, N. T. (2013). Epobf: Energy Efficient Allocation of Virtual Machines in High Performance Computing Cloud. arXiv preprint arXiv:1310.7801. Journal of Science and Technology, 51 (4B),173-182. 
106 Karuppasamy M. and Balakannan S. P.

[29] Kessaci, Y., Melab, N., and Talbi, E. G. (2012). An Energy-Aware MultiStart Local Search Heuristic for Scheduling VMs on the OpenNebula Cloud Distribution. In High Performance Computing and Simulation (HPCS), 2012 International Conference on 112-118.

[30] Kaur, T., and Chana, I. (2016). Energy Aware Scheduling of DeadlineConstrained Tasks in Cloud Computing. Cluster Computing, 19(2), 679-698. doi: 10.1007/s105860160566 9

\section{Biographies}

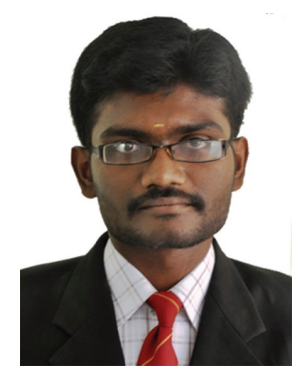

Karuppasamy M. received his Bachelor degree Madurai Kamaraj University, Madurai by 2008. He received his master of Technology in Information Technology from Kalasalingam Academy of Research and Education by 2013. He is working as a Full time Research Scholar in the department of Computer Applications, Kalasalingam Academy of Research and Education. His areas of interest are Cloud Computing. Green Computing and Cloud Networks.

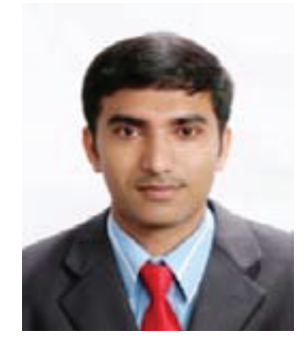

Balakannan S. P. received his Ph.D. degree from the Department of Electronics and Information Engineering at Chonbuk National University, South Korea (2010). He has received his master degree (5 years integrated) 
Energy Saving from Cloud Resources for a Sustainable Green 107

from the Department of Computer Science and Engineering, Bharathiar University, India, in the year 2003. He has worked as a Project Assistant in Indian Institute of Technology (IIT), Kharagpur, India from 2003 to 2006. Currently, he is working as Assistant Professor in the Department of Information Technology, Kalasalingam Academy of Research and Education, Tamilnadu, India. His areas of interest include Wireless Network, Network Coding, Cloud \& Green Computing, Cryptography, and Mobile Communication. 
